\title{
Short communication: Evaluation of bovine milk residues from routine milk testing programs as DNA source for genotyping
}

\author{
K. Krappmann, ${ }^{\star}$ C. Wurmser,† D. Repsilber,‡ R. Fries,† R. Weikard, ${ }^{\star}$ U. Kesting,§ and C. Kühn*1 \\ ${ }^{*}$ Research Unit Molecular Biology, Leibniz Institute for Farm Animal Biology, 18196 Dummerstorf, Germany \\ †Chair of Animal Breeding, Technische Universität München, 85354 Freising, Germany \\ ¥Research Unit Genetics and Biometry, Leibniz Institute for Farm Animal Biology, 18196 Dummerstorf, Germany \\ §Landeskontrollverband für Leistungs- und Qualitätsprüfung Mecklenburg, 18273, Güstrow, Germany
}

\begin{abstract}
Genome-wide association studies and genomic evaluation using a dense set of genetic markers both require a large number of genotyped individuals. Collection of the respective samples contributes substantially to the cost of the approach. In dairy cattle research, the use of residues from routine milk recording would be a costsaving alternative to obtain samples for an appropriate number of individuals with specific phenotypes in a very short time. To assess the suitability of milk recording residues, we concurrently investigated milk residues obtained after standardized milk recording procedures and blood samples from 115 cows originating from 3 farms with different milking systems by genotyping 15 microsatellite markers. We found that $4 \%$ of the milk samples were possibly assigned to the wrong animal (i.e., conflicts) and that at least $27 \%$ of the milk residues were contaminated, as indicated by an extra allele not present in the blood sample. These additional alleles primarily originated from a sample with a higher somatic cell score that went through the milk sample analyzer in the milk laboratory before the target sample. Furthermore, additional allele carryover was observed across more than one sample, when the difference in somatic cell count between samples exceeded 100,000 cells/mL. Finally, in several samples, the extra allele could not be traced back to previous samples passing through the milk sample analyzer. One source of those contaminations might be sample collection on-farm due to milk traces from the previously milked cow in the hose. No correlation was found between the farm management and conflicts or contaminations. We conclude that residues from routine milk recording are not suitable for genomic evaluation or genome-wide association studies because of the high prevalence of contamination generated at several steps during the collection and processing of milk residual samples.
\end{abstract}

Received December 13, 2011.

Accepted April 22, 2012.

${ }^{1}$ Corresponding author: kuehn@fbn-dummerstorf.de
Key words: lactation, genomic evaluation, genomewide association study, milk residual sample

\section{Short Communication}

Genome-wide association studies (GWAS) are designed to identify chromosomal regions (namely, QTL) and mutations within genes that modulate the expression of an inherited phenotype by applying a dense set of genetic markers. The inclusion of information on QTL into animal breeding programs provides an opportunity to enhance selection response and consequently leads to a genetic improvement of animal productivity (Goddard et al., 2010). Recently, the application of genomic evaluation and selection methods has become available in many countries, and discussion has begun on how to optimally include information from the female population (Spelman et al., 2010). However, GWAS and genomic evaluation depend on genotyping a large number of phenotypically divergent individuals to obtain reasonable power for detection of statistically significant associations or reliable genomic predictions (Sen et al., 2009; Lund et al., 2010). In this respect, efforts for sample collection across a large geographic region (e.g., in a scattered population) or from specific individuals with extreme phenotypes may increase project costs substantially. In addition, the use of invasive sample collection procedures (venipuncture, ear tissue punches) is increasingly drawing criticism with regard to animal welfare.

An alternative, simple, low-cost method for obtaining samples from a high number of individuals within a short period could be the use of residues from routine milk recording. The corresponding officially recorded phenotypes for milk performance and SCS and a wealth of further phenotypes (e.g., calving and fertility data, longevity, body conformation, or milking behavior data) are available from routine milk recording and from herdbook registrations for the large population of German Holstein herdbook dairy cows (1.67 million; ADR 2011). 
Isolation of DNA from somatic cells in residuals of the routine milk control samples would be a convenient method for collecting DNA of a specific subset of cows in the population for GWAS and genomic evaluation. However, before application of this DNA source, it is imperative to confirm the suitability of routine milk control residues for this purpose. To this end, we genotyped, in parallel, milk residuals and corresponding blood samples obtained at 2 different sampling times from 115 cows on 3 farms with different milking systems using 15 microsatellite markers.

During routine milk control, standard milk samples were taken from 115 dairy cows (German Holstein) on 3 farms with different milking systems (DeLaval Flowmaster MM15, DeLaval GmbH, Glinde, Germany; BouMatic Perfection 3000, BouMatic Europe, Remicourt, Belgium; Lemmer-Fullwood Tru-Test Milkmeter, Lemmer-Fullwood GmbH, Lohmar, Germany) in Mecklenburg-West Pomerania (Germany) in 2009. The 50-mL tubes of the routine milk control contain a sodium azide solution as preservative. After routine on-farm collection, the milk samples were transferred to the accredited routine milk-testing laboratory, Landeskontrollverband für Leistungs- und Qualitätsprüfung Mecklenburg. The samples were submitted to routine analyses for fat, protein, lactose, urea content, and SCC using accredited procedures with the MilkoScan FT+ / Fossomatic FC- Combination (Foss, Rellingen, Germany). After analyses, the residual milk samples were stored at $4^{\circ} \mathrm{C}$ for 1 to $7 \mathrm{~d}$ and then sent for DNA isolation.

In 2008, EDTA-stabilized coccygeal blood samples had been taken from the same animals with careful identification of the animals by 2 independent persons.
The samples were frozen at $-20^{\circ} \mathrm{C}$ until DNA isolation. Blood DNA was isolated using the NucleoSpin Blood L kit (Macherey-Nagel, Düren, Germany) according to the manufacturer's instructions.

From the milk samples, cells were collected by centrifugation according to Murphy et al. (2002), and DNA was isolated from the cell pellet using the QIAamp DNA Mini kit (Qiagen, Hilden, Germany) according to the manufacturer's instructions. Afterward, an additional ethanol precipitation was carried out to purify and concentrate the DNA. The respective precipitate was dissolved in $30 \mu \mathrm{L}$ of buffer containing $10 \mathrm{~m} M$ Tris/ $\mathrm{HCl}$ and $1 \mathrm{~m} M$ EDTA. The suitability of modified silica-membrane-based nucleic acid purification had also been demonstrated previously for ovine milk samples (Psifidi et al., 2010). Concentration and quality of the DNA samples from blood and milk were measured with the NanoDrop ND-1000 Spectrophotometer (PEQLAB GmbH, Erlangen, Germany).

Simultaneous genotyping of $60 \mathrm{ng}$ of DNA from blood and milk samples, respectively, was performed for 15 microsatellite markers to test for identical genotypes between DNA sources (Table 1). Genotyping of microsatellite markers was performed according to standard procedures as described by Kühn and Weikard (2007) on a MegaBace capillary sequencer (GE Healthcare, München, Germany). Fragment analysis was carried out by 2 independent persons under manual inspection of each sample using the MegaBace Fragment Profiler software.

The genotype observed from the blood sample was considered the original genotype of an animal. The results obtained from genotyping milk DNA were compared with genotypes from the respective blood DNA

Table 1. Name and position of microsatellite markers on the bovine genome assembly Bos taurus UMD3.1 as well as observed heterozygosity $\left(\mathrm{H}_{0}\right)$, expected heterozygosity $\left(\mathrm{H}_{\mathrm{E}}\right)$, and polymorphism information content (PIC)

\begin{tabular}{|c|c|c|c|c|c|c|}
\hline Number & Name & Chromosome & $\begin{array}{c}\text { Position } \\
(\mathrm{Mb})\end{array}$ & $\mathrm{H}_{0}$ & $\mathrm{H}_{\mathrm{E}}$ & $\mathrm{PIC}$ \\
\hline 1 & BMS574 & 1 & 11.92 & 0.7043 & 0.7036 & 0.6519 \\
\hline 2 & DIK2886 & 1 & 68.70 & 0.4348 & 0.4200 & 0.3985 \\
\hline 3 & BMS922 & 1 & 154.96 & 0.7304 & 0.7124 & 0.6566 \\
\hline 4 & MNB86 & 3 & 25.44 & 0.6000 & 0.7479 & 0.7123 \\
\hline 5 & BP1 & 5 & 12.34 & 0.6174 & 0.6253 & 0.5885 \\
\hline 6 & ILSTS006 & 7 & 96.71 & 0.7217 & 0.6267 & 0.5642 \\
\hline 7 & MNB38 & 8 & 99.22 & 0.5913 & 0.5365 & 0.4368 \\
\hline 8 & BMS2151 & 9 & 2.06 & 0.7130 & 0.7004 & 0.6478 \\
\hline 9 & CSSM38 & 10 & 8.64 & 0.6000 & 0.5988 & 0.5793 \\
\hline 10 & TGLA53 & 16 & 25.79 & 0.8087 & 0.8560 & 0.8388 \\
\hline 11 & DIK2452 & 19 & 3.08 & 0.6435 & 0.6630 & 0.6255 \\
\hline 12 & ILSTS092 & 21 & 44.64 & 0.1130 & 0.1067 & 0.1010 \\
\hline 13 & DIK4391 & 21 & 50.22 & 0.7043 & 0.6524 & 0.6027 \\
\hline 14 & INRA201 & 28 & 1.20 & 0.6783 & 0.6804 & 0.6224 \\
\hline 15 & IDVGA 43 & 28 & 26.73 & 0.3913 & 0.5969 & 0.5267 \\
\hline
\end{tabular}


Conflict

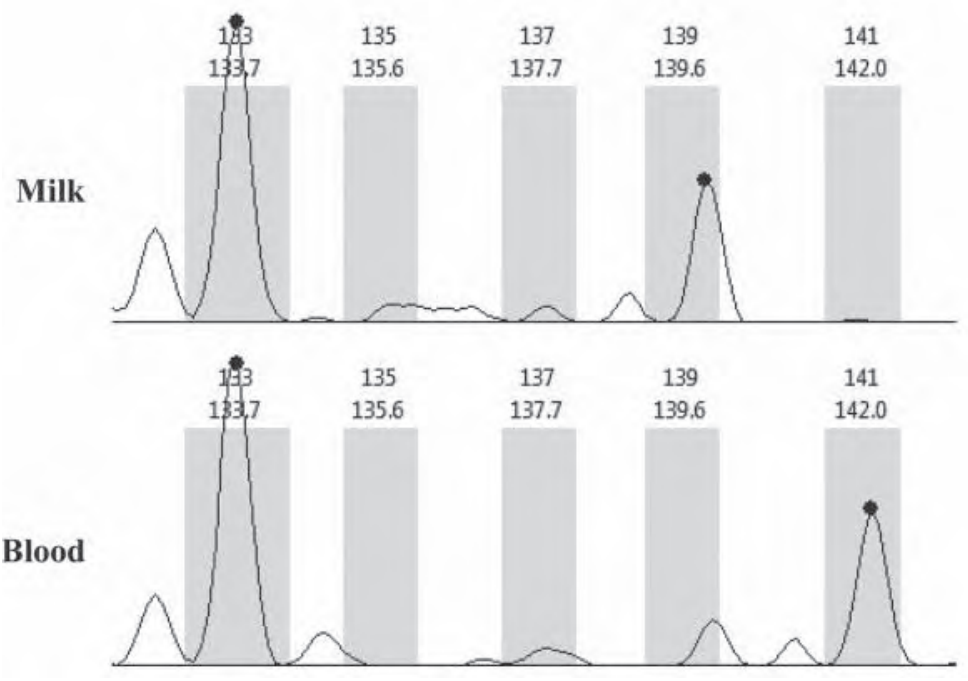

Contamination

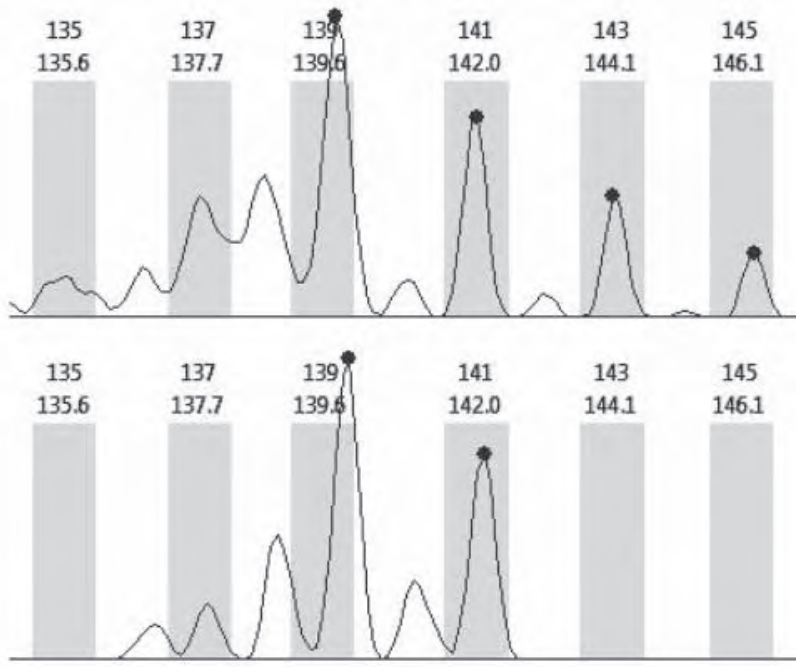

Figure 1. Illustration of a conflict and a contamination case between pairs of blood and milk samples. Alleles are indicated by black dots.

to identify potential discrepancies, which were classified as conflict or contamination. Only those discrepancies between genotypes from a blood and milk DNA sample pair were considered if they were detected for at least 2 markers and were confirmed by 2 independent analyses. The most severe category "conflict case" was assigned to the milk sample of an individual if at least 2 of the markers showed alleles in the blood DNA that were absent in the milk DNA sample (Figure 1). This discrepancy of missing alleles in the milk sample cannot be explained by milk sample contamination. The milk samples from individuals with all other confirmed differences in genotypes between milk and blood sample were classified as a "contamination case." For the conflict category, this is a conservative interpretation, because additional alleles in the milk sample might also be due to conflicts regarding the identity of the sample.

For all markers, observed and expected heterozygosity and polymorphism information content were calculated. Two probabilities were calculated based on Weller et al. (2006): the probability that 2 individuals by chance should have the same genotypes $\left(P_{0 . N}\right)$ for all markers tested and the probability that 2 individuals by chance share the same genotypes except for one divergent marker genotype $\left(P_{1, N}\right)$. Probability $P_{0, N}$ for markers 1 to $\mathrm{N}$ is

$$
P_{0, N}=\prod_{i=1}^{N} x_{i}
$$

where $x_{i}$ is the probability of an identical genotype at marker $i$ :

$$
x_{i}=\left(\sum_{j=1}^{r_{i}} q_{i j}^{4}+4 \sum_{j=1}^{r_{i}-1} \sum_{k=j+1}^{r_{i}} q_{i j}^{2} q_{i k}^{2}\right),
$$

with $r_{i}$ being the number of alleles for marker $i$, and $q_{i j}$ being the frequency of allele $j$ of marker $i$. Finally, $P_{1, N}$ is

$$
P_{1, N}=\sum_{l=1}^{N}\left[\left(1-x_{l}\right) \prod_{m=1}^{l-1} x_{m} \prod_{n=l+1}^{N} x_{n}\right],
$$

where the $l$ th marker is different for 2 individuals, and $x_{m}$ and $x_{n}$ are the probabilities that 2 individuals have identical genotypes for the markers 1 to $l-1$ and $l+1$ to $N$, respectively.

All further statistical analyses were performed using SAS 9.2 (SAS Institute Inc., Cary, NC). Somatic cell score was calculated by logarithmic transformation (Ali and Shook, 1980): SCS $=\log _{2}(\mathrm{SCC} / 100,000)+3$. After testing for normal distribution, differences of SCS, milk yield, and DNA purity between the farms were analyzed using a 2-sample $t$-test. The yield of DNA was not normally distributed; thus, the Wilcoxon-MannWhitney test with the PROC NPAR1WAY statement was applied.

To test the hypothesis that during processing in the MilkoScan FT+/Fossomatic FC machine, a milk residue sample with a higher SCS than the subsequent sample could contaminate the subsequent sample, the data set was screened for pairs of respective, successive genotyped samples. These samples were checked for 
Table 2. Overview of the farms, their milking system, the number (N) of samples, the mean and standard deviation of milk yield (MY) and SCS of the respective individuals, and the number of conflicts and contaminations in the milk DNA samples

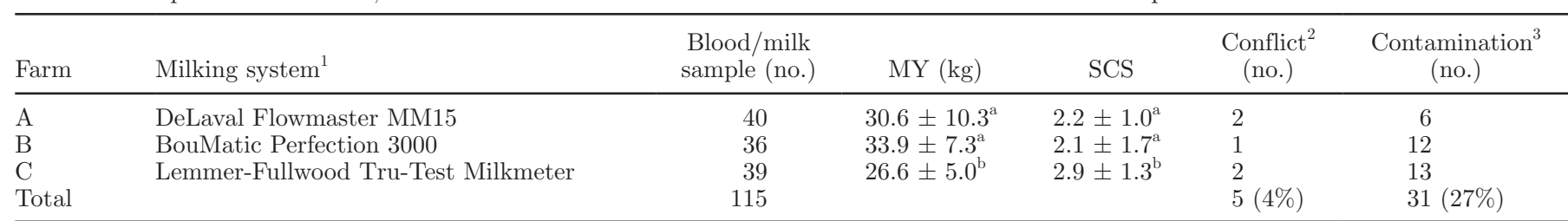

$\overline{{ }^{a}, \mathrm{~b}}$ Means within a column with different superscripts differ significantly $(P<0.05)$.

${ }^{1}$ DeLaval Flowmaster MM15 (DeLaval GmbH, Glinde, Germany); BouMatic Perfection 3000 (BouMatic Europe, Remicourt, Belgium); LemmerFullwood Tru-Test Milkmeter (Lemmer-Fullwood GmbH, Lohmar; Germany).

${ }^{2} \mathrm{~A}$ conflict case was assigned to an individual if at least 2 markers showed alleles in the blood DNA that were not present in the DNA sample obtained from milk.

${ }^{3}$ All other genotype differences between milk and blood samples were classified a contamination case of the milk residual sample if discrepancies were confirmed for at least 2 markers.

putative allele carryover from one sample to the other. Two groups were created: group 1 contained pairs of genotyped samples where the SCS of the second sample was lower than that of the first sample of the pair, and group 2 contained pairs of genotyped samples where the SCS of the second sample was higher than that of the first sample. Both groups were compared using the Fisher test with the PROC FREQ statement. Analogously, to evaluate a potential farm influence, the distribution of conflicts and contaminations across the farms was tested.

The milk yield of farms A and B was different $(P<$ $0.05)$ from that of farm $\mathrm{C}$, and the SCS differed $(P<$ 0.01 ) between farms A and B and farm C (Table 2). Furthermore, a significant difference between farm A and the others was found when comparing the DNA amount obtained from the residual milk samples $(P$ $<0.01$ ) and the ratio of absorbance at $260 \mathrm{~nm}$ and $280 \mathrm{~nm}$, an indicator of DNA quality $(P<0.001)$. Observed and expected heterozygosity, as well as the polymorphism information content values of the 15 microsatellite markers, are listed in Table 1 . The probabilities that 2 individuals by chance should have the same genotype at all markers investigated or the same genotypes except one divergent marker genotype were $5.6 \times 10^{-12}$ and $5.0 \times 10^{-10}$, respectively.

Altogether, only $4 \%$ out of the 115 blood-milk pairs indicated a confirmed conflict between the 2 sources of DNA (Table 2). In contrast, the fraction of blood-milk pairs with a strong indication of contamination of milk samples amounted to $27 \%$. It has to be noted that this is the minimal number of conflicts and contaminations. The limited amount of DNA obtained from some milk samples did not allow us to replicate all genotypes for all markers or to pursue all tentative cases, when only one marker genotype indicated a conflict or contamination. A comparison between the farms revealed no significant difference in the distribution of conflicts and contaminations (Table 2).

An overview of the distribution of contaminated samples in groups 1 and 2 is given in Table 3 . The proportion of contaminated samples was much higher for group 1, in which the SCS of the preceding sample was higher than that of the consecutive test sample, compared with group 2, where the SCS of the preceding sample was lower than that of the consecutive test sample. The differences in the numbers of contaminated and noncontaminated samples between groups 1 and 2 were significant $(P<0.01)$; that is, the possibility of contamination increased when a sample with high SCS was followed by a sample with lower SCS (group 1).

Half of the contamination cases could be explained by the previously analyzed sample in the milk analysis laboratory. In some cases, contamination was observed across more samples than just the one immediately following, especially when the SCS difference was large (mostly exceeding 100,000 cells/mL; Table 4).

In addition, several contamination cases could not be traced back to preceding samples, and sometimes only 1 of 2 foreign alleles could be assigned to a specific preceding sample. The incidence of the contaminating alleles corresponded to the allele frequencies at the re-

Table 3. Overview of the number of contaminated and noncontaminated test samples in group 1 (preceding sample with higher SCS compared with test sample) and 2 (preceding sample with lower SCS compared with test sample) $)^{1}$

\begin{tabular}{lcc}
\hline Test sample & Group $1^{\mathrm{a}}$ & Group $2^{\mathrm{b}}$ \\
\hline Contaminated & 9 & 2 \\
Not contaminated & 8 & 19 \\
Total & 17 & 21 \\
\hline
\end{tabular}

${ }^{a, b}$ Groups 1 and 2 differ regarding contaminated samples $(P<0.01)$. ${ }^{1}$ Only pairs of respective successive genotyped samples were included. 
Table 4. Example for contaminating allele carryover across more than one sample

\begin{tabular}{llcccc}
\hline Microsatellite & Sample $^{1}$ & Allele 1 & Allele 2 & Allele 3 & SCS \\
\hline BMS922UP2 & Blood 1 & 70 & 72 & & \\
BMS922UP2 & Milk 1 & 70 & 72 & & 6.89 \\
BMS922UP2 & Blood 2 & 72 & 72 & & 4.52 \\
BMS922UP2 & Milk 2 & 72 & 72 & & \\
BMS922UP2 & Blood 3 & 72 & 74 & 74 & 0.36 \\
BMS922UP2 & Milk 3 & 70 & 72 & 74 \\
\hline
\end{tabular}

${ }^{1}$ Blood 1 and milk $1=$ blood and milk samples from animal 1 (other sample pairs analogous). Order of measurement with the analytic MilkoScan FT+ or Fossomatic FC apparatus (Foss, Rellingen, Germany) = milk 1-milk 2-milk 3.

spective loci, and no preferential incidence of specific alleles (data not shown) was observed.

The aim of the study was to test whether bovine milk sample residues from routine milk control samples might be a suitable source of DNA for GWAS and genomic evaluation. For this purpose, microsatellite markers instead of SNP were selected due to their high information content and because of their higher number of alleles. These properties make it easier to trace allele carryover than with SNP.

The main reasons for conflicts between milk and blood sample DNA could be sampling errors during sample collection on farm, during sample processing at the milk control laboratory, or during DNA sample preparation and genotyping. A correct animal identification and pedigree is essential for reliable genetic evaluations (Banos et al., 2001) and for an unimpaired genetic progress (Israel and Weller, 2000). Visscher et al. (2002) estimated a pedigree error rate of $13.1 \%$ for milk samples and predicted a large resultant effect on breeding values and on the efficiency of progeny testing. Another study, which also investigated the usefulness of milk residuals for genotyping, found $8 \%$ false identities (Buitkamp and Götz, 2004) and reported contamination as the most frequent source of inconsistencies. Hüttl (2001) found alleles from at least one other cow in $10.6 \%$ of milk samples collected via a milk robot. The contamination rate in our study totaled $27 \%$ of all samples. The reasons for contamination could be milk traces from the previously milked cow in the hose during sample collection on farm or milk carryover during the procedures in the milk testing laboratory, where no regular cleaning is performed between samples during the different milk content measurements. In the study of Hüttl (2001), the analyzed milk samples had not passed through a milk laboratory. Thus, the level of contamination cases $(10.6 \%)$ observed in that data set might be an indicator of the frequency of contamination due to on-farm sample collection, at least for milk robot systems.

In our study, contamination cases were observed on all farms. We found no significant difference between farms, and no influence of the milking system or management practices was apparent. Thus, the data of all farms were merged for the analysis of potential allele carryover between milk sample residues at the milk control laboratory. The results showed that the probability of contamination increases when a sample with high SCS is followed by a sample with lower SCS. Hüttl (2001) determined that a milk sample must contain $20 \%$ foreign cells to enable identification of a foreign allele. Although we detected a substantial carryover between adjacent samples in our study, half of the contamination cases could not be assigned to preceding samples. This suggested that contamination might already have occurred on the farm during the sample collection process in the milking parlor. During the normal milking process in the parlor, small fractions were collected from the whole milk volume into a reservoir. This reservoir was not entirely cleaned from cow to cow before the collected milk fractions were transferred to a sampling tube for official milk recording analytics.

Some milk samples had a preceding sample of substantially higher SCS in the milk laboratory but showed no contamination. This indicated that contamination is a random process and does not occur in all cases. The lack of contamination detection in samples following a sample of higher SCS could not be attributed to identical genotypes of both samples. In fact, only a few respective sample pairs shared the same alleles at single markers; that is, cases of contamination would have been detected.

We must question whether the contaminated samples assigned to group 2 could really have been contaminated by the sample with the lower SCS before them. Consider a potential contamination during milk sample processing of a $0.5-\mathrm{mL}$ carryover from a previous low SCS sample into the regular 50-mL milk volume of the subsequent high SCS sample: this would result in a low concentration of any allele specific to the contaminating sample. Consequently, this allele would yield a very low signal in the microsatellite analysis and would barely be detectable during genotyping. Thus, presumably those samples assigned to group 2 had contamination 
that could not be related to the immediately preceding sample. The origin of the contamination could not be determined unequivocally, although data from Hüttl (2001) suggest that a substantial proportion might result from sample collection on farm. Because of the high proportion (27\%) of contaminated samples and the divergent origin of the allele carryover, we conclude that bovine milk sample residues from routine milk control are currently not a reliable sample source for GWAS and genomic evaluations. Improved cleaning procedures during on-farm sample collection as well as during sample processing for milk control analytics would require a substantially modified routine process. Alternatively, sample sorting for SCS before milk control analytics might be possible if data from on-farm SCS data recording were available before analysis in the milk laboratory. Under the high-throughput conditions of milk laboratories optimized for low cost, this would require extra sorting procedures, which would increase the cost of milk recording. However, the focus of our analysis was the evaluation of a cost-saving method for sample collection from many animals in a very short time. Thus, it is unlikely that the effort would be worthwhile to validate the efficiency of sample sorting according to unofficial on-farm SCS records for decreasing the rate of contamination.

\section{ACKNOWLEDGMENTS}

The work was supported by the German Federal Ministry of Education and Research (BMBF) within the scope of the FUGATO MeGA-M project (FKZ 0315131C, FKZ 0315131A). The technical support from S. Wöhl and A. Lehmann from the Leibniz Institute for Farm Animal Biology, Research Unit Molecular Biology (Dummerstorf, Germany) is gratefully acknowledged.

\section{REFERENCES}

ADR (Arbeitsgemeinschaft deutscher Rinderzückter). 2011. Rinderproduktion in der Bundesrepublik Deutschland 2010. Arbeitsgemeinschaft deutscher Rinderzückter e.V. (ADR), Bonn, Germany.
Ali, A. K. A., and G. E. Shook. 1980. An optimum transformation for somatic cell concentration in milk. J. Dairy Sci. 63:487-490.

Banos, G., G. R. Wiggans, and R. L. Powell. 2001. Impact of paternity errors in cow identification on genetic evaluations and international comparisons. J. Dairy Sci. 84:2523-2529.

Buitkamp, J., and K.-U. Götz. 2004. Use of milk samples from a milk evaluation program for the genotyping of cows. Arch. Tierzucht. $47: 15-26$.

Goddard, M. E., B. J. Hayes, and T. H. E. Meuwissen. 2010. Genomic selection in livestock populations. Genet. Res. (Camb.) 92:413-421.

Hüttl, K. 2001. Genetische Qualitätssicherung von Milch- und Spermaproben beim Rind. Doctoral Thesis. Ludwig-Maximilian-Univ., München, Germany.

Israel, C., and J. I. Weller. 2000. Effect of misidentification on genetic gain and estimation of breeding value in dairy cattle populations. J. Dairy Sci. 83:181-187.

Kühn, C., and R. Weikard. 2007. An investigation into the genetic background of coat colour dilution in a Charolais $\times$ German Holstein F2 resource population. Anim. Genet. 38:109-113.

Lund, M. S., A. P. W. de Roos, A. G. de Vries, T. Druet, V. Ducrocq, S. Fritz, F. Guillaume, B. Guldbrandtsen, Z. Liu, R. Reents, C. Schrooten, M. Seefried, and G. Su. 2010. Improving genomic prediction by EuroGenomics collaboration. Page 150 in Proc. 9th World Congr. Genet. Appl. Livest. Prod. German Society for Animal Science, Leipzig, Germany.

Murphy, M. A., M. R. Shariflou, and C. Moran. 2002. High quality genomic DNA extraction from large milk samples. J. Dairy Res. 69:645-649.

Psifidi, A., C. I. Dovas, and G. Banos. 2010. A comparison of six methods for genomic DNA extraction suitable for PCR-based genotyping applications using ovine milk samples. Mol. Cell. Probes 24:93-98.

Sen, S., F. Johannes, and K. W. Broman. 2009. Selective genotyping and phenotyping strategies in a complex trait context. Genetics 181:1613-1626.

Spelman, R. J., J. Arias, M. D. Keehan, V. Obolonkin, A. M. Winkelman, D. L. Johnson, and B. L. Harris. 2010. Application of genomic selection in the New Zealand dairy cattle industry. Page 159 in Proc. 9th World Congr. Genet. Appl. Livest. Prod. German Society for Animal Science, Leipzig, Germany.

Visscher, P. M., J. A. Woolliams, D. Smith, and J. L. Williams. 2002. Estimation of pedigree errors in the UK dairy population using microsatellite markers and the impact on selection. J. Dairy Sci. $85: 2368-2375$.

Weller, J. I., E. Seroussi, and M. Ron. 2006. Estimation of the number of genetic markers required for individual animal identification accounting for genotyping errors. Anim. Genet. 37:387-389. 